\title{
Design Participativo no Ensino Médio: Desenvolvimento de um Jogo Auxiliar ao Processo de Ensino
}

\author{
Gian Lucca M. Flores ${ }^{1}$, Rudieri D. Bauer ${ }^{1}$, Ângelo N. V. Crestani ${ }^{1}$, \\ André Luiz Montanha ${ }^{1}$, Jaline Gonçalves Mombach ${ }^{1}$ \\ ${ }^{1}$ Instituto Federal de Educação, Ciência e Tecnologia \\ Farroupilha (IFFarroupilha) - Campus Alegrete \\ Caixa Postal 118 - 97.555-000 - Alegrete - RS - Brazil \\ \{gianlucamottaflores, rudierib, angelovieira.c, alm28062001\}@gmail.com \\ jaline.mombacheiffarroupilha.edu.br
}

\begin{abstract}
The methodologies of Formative Evaluation and Gamification can be interconnected by the continuous monitoring of the student. However, there are few technological tools that adopt these approaches to support teaching. Therefore, this paper describes the experience of a three-dimensional game, developed by undergraduate students, together with high school students, applying Participatory Design concepts. The development includes three iterative steps: brainstorming, prototyping, and evaluation. The preliminary results show two prototypes assessment and good acceptance by participants, as well as greater involvement in the curricular content.
\end{abstract}

Resumo. As metodologias de Avaliação Formativa e Gamificação podem ser interligadas pela característica de acompanhamento contínuo do aluno. Porém, são poucas as ferramentas tecnológicas que adotam essas abordagens para apoiar o ensino. Dessa forma, este artigo relata a experiência sobre um jogo tridimensional, desenvolvido por alunos do ensino superior, juntamente a alunos do ensino médio, aplicando conceitos de Design Participativo. O desenvolvimento inclui três fases iterativas: brainstorming, prototipação e avaliação. Os resultados preliminares mostram duas avaliações em protótipos e boa aceitação por parte dos alunos do ensino médio, além de maior envolvimento no conteúdo curricular.

\section{Introdução}

A avaliação é uma etapa essencial para verificação da aprendizagem e diferentes metodologias estão sendo discutidas, visto que o formato tradicional tem sido criticado por alguns pesquisadores da área. Gomes et al. (2015) salientam que a estratégia mais clássica, associada à aprendizagem passiva e individual, limita-se à aplicação de exames e não favorece o pensamento crítico e lógico dos alunos sobre o conhecimento adquirido. Além disso, os autores também enfatizam que habilidades de comunicação, trabalho em grupo e resolução de problemas não são explorados nesses modelos de avaliação.

Nesse sentido, a Avaliação Formativa aparece como opção aos educadores. Apesar de ter surgido há quase quatro décadas, ainda tem pouco destaque no ambiente educacional (DUTRA; TAROUCO; PASSERINO, 2011). Proposta por Scriven (1967), essa 
metodologia evidencia que o processo de avaliação é contínuo e participativo com ênfase no feedback de alunos e professores envolvidos é um dos diferenciais. É possível encontrar diferentes ferramentas tecnológicas para apoio ao ensino, porém, percebe-se que poucas adotam metodologias pedagógicas e restringem-se mais ainda quando o públicoalvo são alunos do Ensino Médio.

Sabe-se que para o desenvolvimento de ferramentas tecnológicas, o Design Participativo (DP) apresenta-se como método consolidado para investigação, visto que determina técnicas para auxiliar nas soluções que atendam às necessidades do usuário final e a participação de diferentes partes interessadas no sistema de informação (MELO; BARANAUSKAS; SOARES, 2008).

Dessa forma, este artigo apresenta um breve relato de experiência sobre o desenvolvimento de um jogo auxiliar ao processo de ensino, baseado em Avaliação Formativa, concebido inteiramente por alunos do ensino superior, juntamente a alunos do ensino médio, aplicando conceitos de Design Participativo.

O trabalho está organizado da seguinte forma: além desta Introdução, na Seção 2 descreve-se detalhadamente o Design Participativo e conceitos de Gamificação; na Seção 3, apresentam-se os trabalhos relacionados; na Seção 4, explica-se o jogo tridimensional desenvolvido; na Seção 5, relata-se a avaliação da atividade pelos alunos; Por fim, na Seção 6 realizam-se as considerações finais.

\section{Avaliação Formativa e Gamificação}

Nesta seção são apresentados conceitos de Avaliação Formativa e Gamificação, fundamentando tais métodos e discutindo sobre como podem contribuir para uma aprendizagem mais significativa.

A avaliação é um dos elementos mais importantes no contexto educacional, pois permite que os alunos demonstrem suas habilidades, de modo que docentes entendam seu atual nível de aprendizagem, identificando lacunas de conhecimento ou aspectos a serem melhor trabalhados. Assim, professores podem adaptar os materiais de aula conforme as necessidades dos discentes. Todavia, realizar uma avaliação eficaz não é uma tarefa trivial, ao passo que esse processo envolve diversos aspectos como motivação do aluno e análise de comportamento durante a realização das atividades (GIKANDI; MORROW; DAVIS, 2011).

Nesse contexto, a avaliação formativa emerge como uma solução viável por enfatizar o uso de metodologias que permitem que professores monitorem de forma constante e aprofundada o processo estudantil, de modo que possam não somente detectar as dificuldades dos alunos, mas também identificar padrões de aprendizagem que podem ser usados para a qualidade do processo de ensino e aprendizagem (CAULEY; MCMILLAN, 2010).

Diferente da avaliação sumativa, que enfatiza a coleta de informações sobre o progresso estudantil ao final de determinado período instrucional (por exemplo, ao final do semestre ou após exploração de determinado grupo de conteúdos), o principal objetivo da avaliação formativa é permitir a coleta detalhada de informações sobre os discentes enquanto esses realizam suas atividades. Assim, a avaliação formativa se destaca por oferecer um maior nível de detalhes sobre o processo de aprendizagem, permitindo 
VI Congresso Brasileiro de Informática na Educação (CBIE 2017)

Anais dos Workshops do VI Congresso Brasileiro de Informática na Educação (WCBIE 2017)

que professores compreendam mais facilmente onde estão as dificuldades de seus alunos (BENNETT, 2011).

Outra metodologia não convencional que vem ganhando espaço nas salas de aula é a Gamificação, que consiste em inserir elementos de jogo no processo de ensino e aprendizagem. O engajamento dos alunos em sala de aula é um fator de extrema importância, pois é um dos elementos que influenciam diretamente no progresso discente. Como a metodologia adotada pelos professores exerce influência sobre o engajamento estudantil, há uma preocupação em desenvolver atividades que sejam compatíveis com os interesses dos discentes (MORAES; VARELA, 2007).

A Gamificação surge então com a proposta de aplicar elementos oriundos de jogos em atividades educacionais. Além da ludicidade, essa metodologia oferece a professores diversos recursos como sistemas feedback, que guiam o aluno no decorrer das tarefas através de instruções simples e objetivas que podem ajudar os discentes na compreensão de novos conceitos (MENEZES; BORTOLLI, 2016). Outro recurso apresentado por essa metodologia são os sistemas de pontuação, que podem ser usados para motivar os alunos melhorar seu rendimento nas atividades e também permitem que professores acompanhem o progresso dos discentes, identificando por exemplo conceitos mal compreendidos ou lacunas de conhecimento.

Conforme Menezes e Bortolli (2016), a Gamificação pode ser interligada à Avaliação Formativa principalmente pela característica evolutiva de ambas, ou seja, em uma ambiente gamificado é importante que o aluno perceba o seu progresso e/ou regresso durante a realização dos desafios impostos. Os autores descrevem que se for utilizada da maneira adequada, a gamificação tem a capacidade de aumentar a eficácia da avaliação formativa.

\section{Trabalhos Relacionados}

A fim de aumentar o interesse e melhorar o desempenho escolar dos aprendizes, vários estudos apresentam a aplicação e as experiências obtidas com a adoção da gamificação, assim como a utilização de Design Participativo no processo de ensino.

Mesquita et al. (2014) realizaram um estudo que envolve a utilização de uma Rede Social e conceitos de gamificação, como pontos, níveis e quadros de líderes para melhorar a participação dos alunos. Após coleta dos dados e avaliação dos resultados, verificou-se que o principal objetivo do projeto foi alcançado, pois a maioria dos alunos apresentou melhor desempenho utilizando os conceitos de gamificação do que um ambiente educacional convencional.

Por sua vez, Ibáñez, Di-Serio e Delgado-Kloos (2014) avaliaram a eficácia da aprendizagem em relação ao engajamento dos alunos durante a realização de uma atividade de aprendizagem gamificada voltada para a aprendizagem da linguagem de programação C. O estudo também buscou indagar aos alunos quais das atividades aplicadas eram mais atraentes. Como análise, foram coletados dados referentes a registros e questionários. Os resultados da avaliação mostram efeitos positivos sobre os alunos em relação às atividades de aprendizagem gamificada e uma melhora moderada nos resultados da aprendizagem.

Já Toda et al. (2016) relatam um modelo conceitual de processo de gamificação 
destinado à alunos de cursos de graduação. O modelo desenvolvido descreve quatro fases para aplicação da gamificação: definição de conteúdo, definição de elementos de jogos, implantação e validação. Para analisar a eficácia da proposta, foi utilizado o Intrinsic Motivation Inventory (IMI) que mede a motivação dos discentes após o uso da gamificação. Ao final, os autores enfatizam que o método apresentado foi considerado divertido e interessante pelos alunos, além de ter obtido boa aceitação dos docentes.

O projeto DEMULTS apresentado em Morais, Gomes e Peres (2012), propõe a utilização de DP a fim de buscar a relação entre educação, inclusão e tecnologia, de maneira que os usuários finais façam parte de todo o processo de desenvolvimento. Também, Matsunaga et al. (2012) apresentam utilização de técnicas de gamificação juntamente ao DP, a fim de desenvolver um jogo educativo que busca auxiliar crianças com hemofilia a terem maior aderência ao tratamento prescrito.

Soares, Gonçalves e Magalhães (2011) desenvolveram um software educacional com o intuito de atrair a atenção dos alunos durante o aprendizado de conteúdos escolares relacionados à disciplina de Química. Assim, o estudo objetivou-se na criação de um jogo 3D com conteúdos relacionados à referida disciplina. A plataforma utilizada para a implementação do jogo foi a Unreal Engine. Dessa forma, de maneira semelhante, a próxima Seção apresenta o desenvolvimento do jogo tridimensional proposto neste trabalho.

Nesse sentido, diferentemente dos trabalhos destacados, este estudo apresenta o relato das experiências obtidas após o desenvolvimento, aplicação, avaliação e aprimoramento de um jogo tridimensional desenvolvido a fim de contribuir no processo de aprendizagem de estudantes de cursos de tecnologia, especialmente nas disciplinas de iniciação à programação. Os detalhes sobre o desenvolvimento do jogo são apresentados a seguir.

\section{O Jogo: Labirintos de Programação}

A ferramenta utilizada na atividade foi desenvolvida por alunos do ensino superior, vinculados ao projeto de ensino Clube de Realidade Virtual, juntamente com avaliação dos alunos do ensino médio da mesma Instituição. Para a criação do recurso, utilizou-se a plataforma Unity e o software de modelagem Blender. O tema do jogo é introdução à lógica de programação, contemplando uma disciplina do curso técnico em Informática.

A aplicação contempla três labirintos distintos, cada um é uma fase diferente do jogo. O jogador controla um personagem com o objetivo inicial de encontrar e coletar três chaves espalhadas pelo cenário. A ideia das chaves surgiu na primeira interação com a turma, em que se estava planejando o jogo. Após encontrar as chaves, o jogador deve localizar uma porta que lhe dará acesso ao local da questão avaliativa. Inicialmente, há apenas uma questão avaliativa por fase, pois o jogo está em desenvolvimento. As questões foram elaboradas pelos alunos do ensino superior e revisados pela professora da disciplina.

O local das perguntas exibe uma questão referente à disciplina Programação I em uma "parede"e as possíveis respostas encontram-se em três portas. Apenas a porta que tem a resposta correta dará acesso para a próxima fase do jogo, as demais o farão voltar ao ponto inicial da fase em que se encontra, ou seja, terá que percorrer o labirinto novamente em busca das chaves e somente depois que recolhê-las é que poderá responder novamente 
VI Congresso Brasileiro de Informática na Educação (CBIE 2017)

Anais dos Workshops do VI Congresso Brasileiro de Informática na Educação (WCBIE 2017)

a questão. Quando o aluno estiver na terceira e última fase e responder de forma correta a pergunta final, exibe-se uma tela de parabenização por ter alcançado os três níveis e o jogo retorna para o menu inicial. Salienta-se que o nível de complexidade das questões também é progressivo. A Figura 1 ilustra uma das perguntas presentes no jogo.

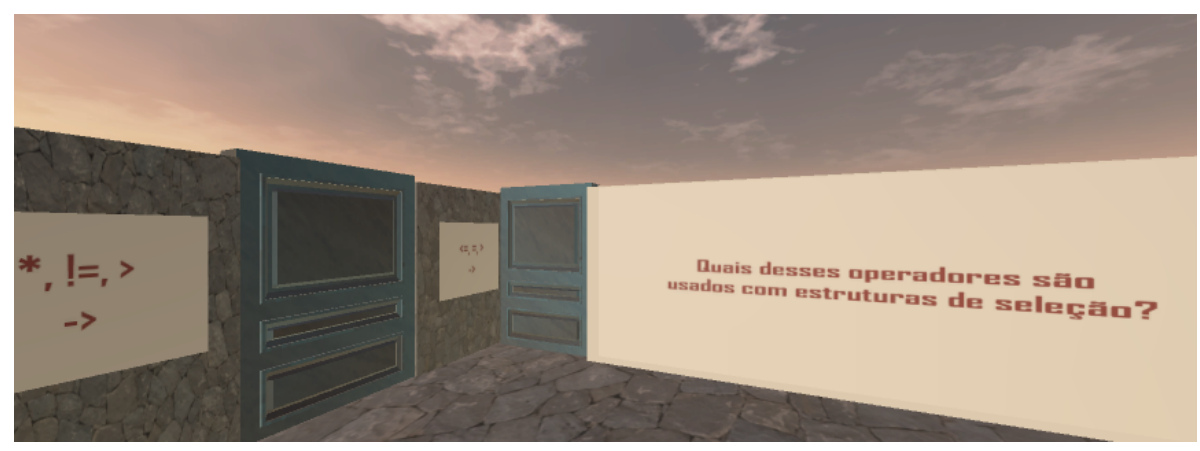

Figura 1. Imagem da pergunta na sala final na primeira fase. A pergunta é "Quais desses operadores são usados com estruturas de seleção?"e as possíveis respostas são exibidas em cada porta.

Baseado no Design Participativo, a ferramenta teve brainstorming inicial para definição do jogo, como os elementos que seriam utilizados, enredo, visão do usuário e questões avaliativas com um grupo formado por 4 alunos voluntários do ensino médio e outros 4 alunos do ensino superior. Após criação do primeiro protótipo houve avaliação com uma turma de 32 alunos do $1^{\circ}$ ano do ensino técnico em Informática e conforme sugestões de melhoria, houve nova avaliação com 12 alunos do mesmo grupo. A Figura 2 ilustra o processo de desenvolvido com Design Participativo. As demais subseções detalham as duas fases de aplicação do jogo para avaliação pelos alunos.

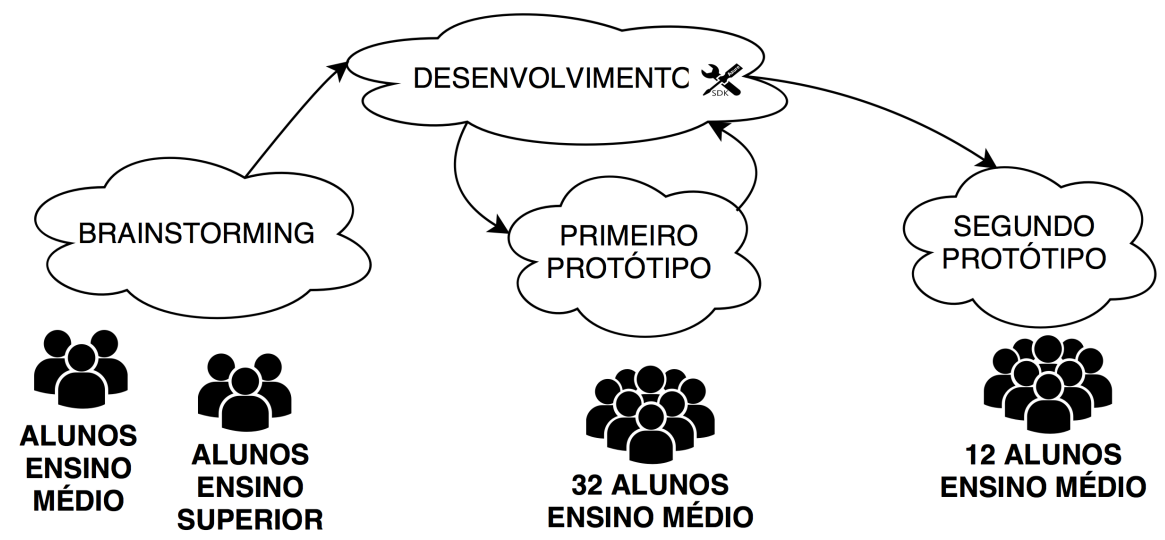

Figura 2. Etapas de elaboração do jogo, baseado no Design Participativo.

\subsection{Primeiro Protótipo}

O jogo Labirintos de Programação foi aplicado com a turma do primeiro ano do Curso Técnico em Informática Integrado do Instituto Federal Farroupilha, Campus Alegrete, Rio Grande do Sul. A atividade contempla uma série de ações do projeto de ensino 
VI Congresso Brasileiro de Informática na Educação (CBIE 2017)

Anais dos Workshops do VI Congresso Brasileiro de Informática na Educação (WCBIE 2017)

Pensar para Programar, que realiza a utilização de diferentes abordagens para estímulo ao raciocínio lógico como forma de auxílio na disciplina de Programação I, sendo uma das estratégias do projeto a gamificação.

A atividade foi aplicada em um laboratório de informática com 32 alunos, em que as idades variavam entre 14 e 19 anos. Inicialmente, toda a turma foi instruída sobre a tarefa que realizariam, salientando-se que tratava-se de uma avaliação. O grupo de alunos que desenvolveu o jogo explicou sobre o funcionamento, os controles e os incentivaram a ler as instruções presentes na aplicação. Os alunos poderiam escolher jogar de forma individual ou em duplas.

Observou-se entusiasmo e curiosidade por parte dos alunos por serem permitidos a jogar no laboratório de informática, aparentemente algo inusitado. No decorrer da atividade, muitos solicitavam os monitores para sanar dúvidas quanto à mecânica do jogo (como pegar as chaves, abrir as portas e etc). Houve problemas de desempenho por conta da incompatibilidade da placa gráfica presente nos computadores e deformação nas cores e iluminação foram relatados pelos alunos.

Devido à experiência prévia em jogos tridimensionais similares à proposta, percebeu-se que alguns alunos apresentaram maior facilidade para realização da atividade, enquanto outros solicitavam mais ajuda dos monitores. Consequentemente, apesar da grande maioria demonstrar determinação e entusiasmo em realizar os desafios propostos, alguns participantes demonstraram preocupação ao não conseguir avançar as fases do jogo e desmotivação ao verificar que outros colegas já haviam concluído a fase inicial. A Figura 3 apresenta registro dos alunos realizando a atividade.
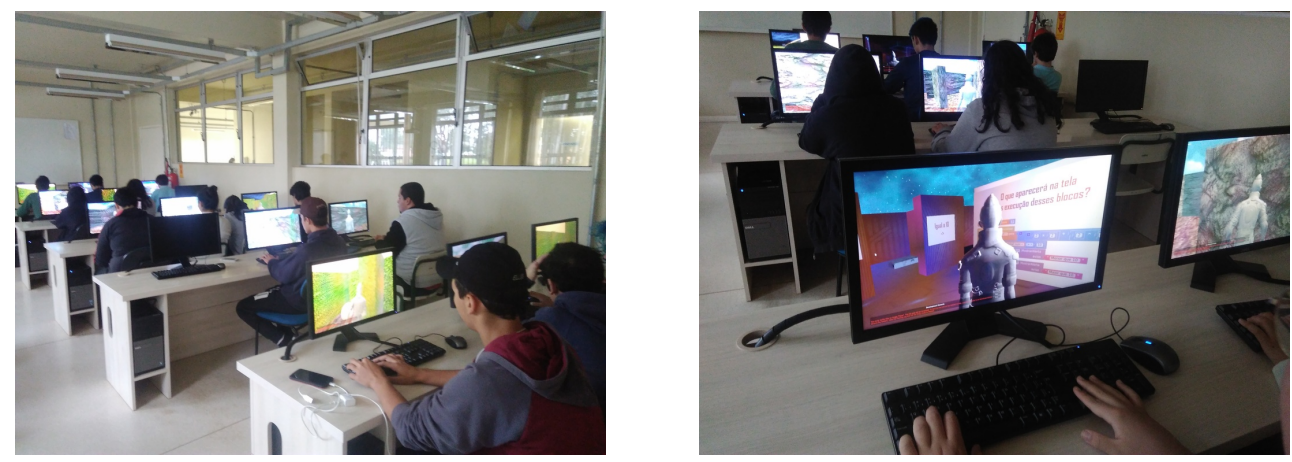

Figura 3. Registro da atividade experimental com os alunos do ensino médio.

Após o período destinado à realização do jogo, somente dois alunos haviam alcançado todas as fases. Então, os monitores propuseram o preenchimento de um formulário avaliativo para que os estudantes pudessem expor sua opinião sobre a realização de uma avaliação em formato de jogo tridimensional e também sugestões de melhoria para a aplicação desenvolvida. A maioria das perguntas foram objetivas:

- Como você usualmente realiza avaliações nas disciplinas? (i) Atividades em livro; (ii) Provas e testes impressos; (iii)Atividades em ambiente on-line; (iv) Outros.

- Com que frequência as atividades avaliativas são realizadas em meios digitais? (i) Nenhuma; (ii) Pouco frequente; (iii) Indiferente; (iv) Frequentemente; (v) Sempre. 
VI Congresso Brasileiro de Informática na Educação (CBIE 2017)

Anais dos Workshops do VI Congresso Brasileiro de Informática na Educação (WCBIE 2017)

- Qual a sua opinião sobre realização de atividades avaliativas em meios digitais? (dissertativa)

- Como você avalia a intervenção realizada em ambiente imersivo (jogo)?(i) Insatisfatória; (ii) Pouco Satisfatória; (iii) Indiferente; (iv) Satisfatória; (v) Muito Satisfatória. Por quê? (dissertativa)

Quanto à maneira como usualmente são realizadas as avaliações nas disciplinas, $78,1 \%$ dos alunos marcaram provas e testes impressos, 34,4\% ambientes on-line e ainda $9,4 \%$ atividades em livro. Na sequência, quanto à frequência em que realizam atividades avaliativas em meios digitais, 46,9\% responderam a opção pouco frequente. Porém, 43,8\% responderam frequentemente. Ainda, 9,4\% preferiram não opinar. Logo, percebese que a turma não tem um conceito definido sobre realização de avaliações em meios digitais.

Em "Qual a sua opinião sobre realização de atividades avaliativas em meios digitais?", a turma expressou-se de forma positiva, conforme apresentado na Figura 4a. Percebe-se que há destaque para "legal", "interessante", "importante", entre outras. Também, ao avaliarem a experiência realizada, solicitava-se o porquê dessa avaliação e entre as respostas há destaque para "divertido" e "gostei", conforme ilustra a Figura 4b.

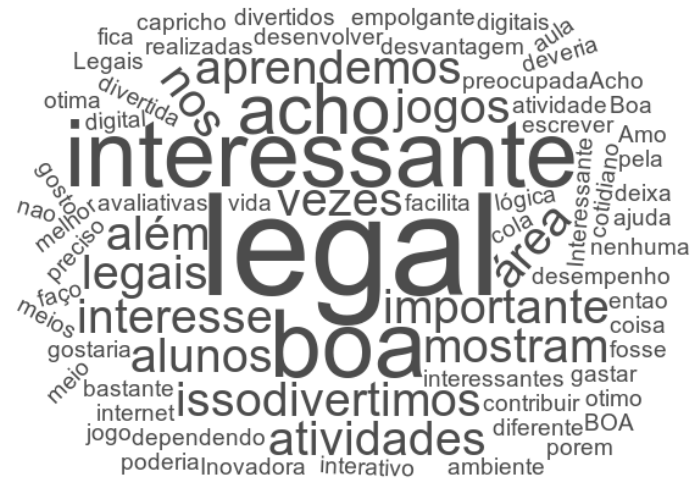

(a)

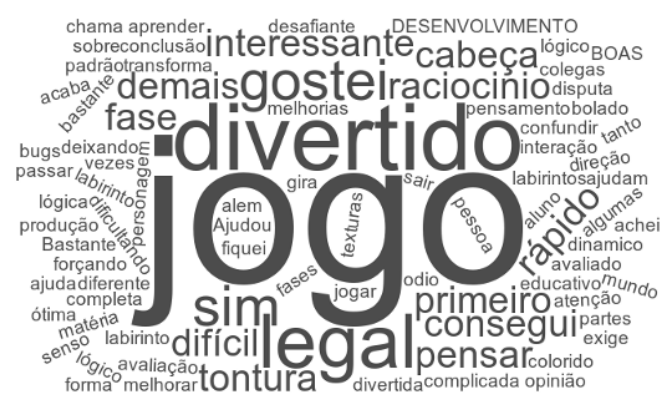

(b)

Figura 4. Nuvem de palavras com as expressões mais utilizadas pelos alunos nas questões abertas do primeiro encontro: (a) Qual a sua opinião sobre realização de atividades avaliativas em meios digitais? e (b) Como você avalia a experiência realizada? Porquê?

A realização do questionário trouxe como resposta uma reação majoritariamente positiva dos alunos, destacam-se respostas como "Porque exige muito pensamento e raciocínio lógico", "Porque o jogo é bastante dinâmico e divertido", "O jogo é de ótima produção muito bem bolado, as cores dos labirintos ajudam muito a confundir nosso senso de direção dificultando a conclusão e deixando o jogo mais difícil", "Ajudou a aprender mais sobre a matéria, e interação com o jogo foi desafiante", "Pois o jogo é divertido, jogar com colegas e ver quem completa as fases primeiro é divertido", "porque é legal e interessante e além de ser divertido faz a pessoa usar o raciocínio", "Porque todo mundo tem que pensar rápido pois é uma disputa para ver quem acaba primeiro, e também porque ajuda a melhorar a lógica do aluno forçando ele a pensar mais rápido". 
VI Congresso Brasileiro de Informática na Educação (CBIE 2017)

Anais dos Workshops do VI Congresso Brasileiro de Informática na Educação (WCBIE 2017)

Dentre as sugestões de melhoria e reclamações observa-se questões como a necessidade de aperfeiçoamento no funcionamento dos controles, a sugestão da ampliação do número de fases, o aumento de possibilidades de interação com o cenário, a necessidade de melhorias em relação a otimização da plataforma assim como correção de erros e resolução de problemas de compatibilidade com placas de vídeo apresentados no decorrer da atividade.

\subsection{Segundo Protótipo}

A mesma turma participou de uma segunda experiência de jogo e avaliação do protótipo. Devido ao teste anterior e experiência com outros jogos tridimensionais, os alunos tiveram maior facilidade quanto à jogabilidade, que havia sofrido alteração apenas na visão do jogador, passando a ser primeira pessoa. Outras mudanças para o segundo teste foram a troca de questões e posição dos objetos necessários para abrir portas, além das instruções mais claras e menu mais intuitivo. Nesta segunda experiência, 12 alunos conseguiram concluir o labirinto inteiro.

Conforme sugerido por diversos alunos foi acrescentado uma fase tutorial, que ensina como jogar e qual o objetivo do jogo. Na Figura 5 é possível visualizar a alteração para visão em primeira pessoa e a fase tutorial, que possui setas apontando os locais e uma mensagem indicando em quais botões clicar.

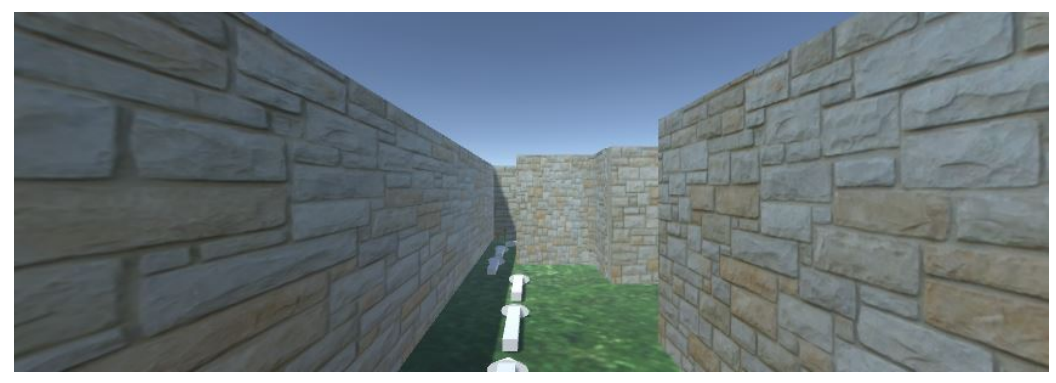

Figura 5. Fase tutorial com visão em primeira pessoa.

Dessa vez, a avaliação foi realizada em questionário com respostas objetivas de -2 (Discordo Fortemente) até +2 (Concordo Fortemente). Esse questionário foi baseado no modelo MEEGA+, proposto por Petri, Wangenheim e Borgatto (2016). Esse modelo de avaliação foi selecionado pelo fato de ser focado em avaliar jogos e ferramentas desenvolvidas em diversas área, podendo ser fortemente adequado para jogos educacionais.

A análise dos dados obtidos reforçaram os pontos a serem evoluídos e aqueles que foram melhorados, permitindo acrescentar novos elementos, necessidades e desafios. A prototipação em desenvolvimento se baseia nos resultados obtidos dos relatórios, levando em consideração a opinião de cada membro e participante do teste.

Destacam-se expressões dos alunos como na afirmação "Este jogo é adequadamente desafiador para mim, as tarefas não são muito fáceis nem muito difíceis." em que o retorno do aluno foi “+2. Muito bom para tarefas de aula", assim como em "Temporariamente esqueci das minhas preocupações do dia-a-dia, fiquei totalmente concentrado no jogo." em que a resposta foi "2 O jogo te prende nele".

Os dados coletados permitem visualizar a evolução do game a partir das mudanças efetivadas com o primeiro questionário, em que foi possível o aperfeiçoamento para 
VI Congresso Brasileiro de Informática na Educação (CBIE 2017)

Anais dos Workshops do VI Congresso Brasileiro de Informática na Educação (WCBIE 2017)

correções de pequenos erros e jogabilidade. Também permite-se detectar novas necessidades, como na questão "Foi fácil entender o jogo e começar a utilizá-lo como material de estudo." em que obtivemos respostas como " $(+1)$ acho que tinha que ter mais perguntas sobre o conteúdo". Nota-se com esta resposta que os discentes sentiram a carência de mais questões abordando os temas de aula, o que consequentemente resulta em novas fases ou uma nova abordagem no jogo.

\section{Considerações Finais}

Diversos estudos têm sido empreendidos em busca de métodos e técnicas que possam aumentar a efetividade da utilização de ferramentas para o meio educacional. Dentre as abordagens analisadas, o design participativo se demonstra como alternativa a ser estudada por conta de possibilitar que o produto a ser desenvolvido seja avaliado por usuários pertencentes ao público alvo, possibilitando assim que seja obtida uma maior taxa de eficácia na ferramenta.

Desta maneira, o presente trabalho apresenta uma ferramenta interativa em ambiente virtual voltada à educação que visa o ensino de programação, a ferramenta desenvolvida consiste em um jogo virtual na perspectiva de terceira pessoa onde os jogadores são apresentados a um labirinto e desafiados a concluí-lo. A ferramenta está sendo desenvolvida em conjunto com alunos do ensino médio e até o momento já foram realizadas duas experiências práticas junto ao estudantes.

Um dos problemas encontrados durante a realização da atividade foi durante a execução do jogo nos computadores do laboratório. Devido à limitações de hardware, ocorreu o aparecimento de artefatos gráficos na execução do jogo, tais como: lentidão, alteração nas cores, textura e materiais no cenário.

De modo geral, resultados obtidos através da realização da atividade demonstram que a estratégia utilizada obteve sucesso na realização do objetivo proposto, provando assim a validade da metodologia empregada. A ferramenta desenvolvida foi considerada efetiva por parte dos discentes envolvidos na atividade, os quais a destacam como um método eficaz dentro do contexto utilizado, bem como a equipe observou sinais de evolução nos alunos quando comparado à primeira experiência com a ferramenta.

Para trabalhos futuros visa-se o aperfeiçoamento e expansão do jogo, tal como melhorias de jogabilidade, introdução de novas fases, cenários e desafios de modo que venham a tornar a ferramenta mais atrativa a jovens estudantes. Modificações que podem ser filtradas com o levantamento de dados do modelo MEEGA+, havendo a necessidade de uma nova aplicação do protótipo para sustentar a efetividade das mudanças.

\section{Referências}

BENNETT, R. E. Formative assessment: A critical review. Assessment in Education: Principles, Policy \& Practice, Taylor \& Francis, v. 18, n. 1, p. 5-25, 2011.

CAULEY, K. M.; MCMILLAN, J. H. Formative assessment techniques to support student motivation and achievement. The Clearing House: A Journal of Educational Strategies, Issues and Ideas, Taylor \& Francis, v. 83, n. 1, p. 1-6, 2010. 
VI Congresso Brasileiro de Informática na Educação (CBIE 2017)

Anais dos Workshops do VI Congresso Brasileiro de Informática na Educação (WCBIE 2017)

DUTRA, R. L. de S.; TAROUCO, L. M. R.; PASSERINO, L. Utilização de objetos de aprendizagem abertos scorm para dar suporte à avaliação formativa. Brazilian Journal of Computers in Education, v. 18, n. 03, p. 59, 2011.

GIKANDI, J. W.; MORROW, D.; DAVIS, N. E. Online formative assessment in higher education: A review of the literature. Computers \& education, Elsevier, v. 57, n. 4, p. 2333-2351, 2011.

GOMES, T. et al. Avaliação de um jogo educativo para o desenvolvimento do pensamento computacional na educação infantil. In: Anais dos Workshops do Congresso Brasileiro de Informática na Educação. [S.1.: s.n.], 2015. v. 4, n. 1, p. 1349.

IBÁÑEZ, M.-B.; DI-SERIO, A.; DELGADO-KLOOS, C. Gamification for engaging computer science students in learning activities: A case study. IEEE Transactions on Learning Technologies, IEEE, v. 7, n. 3, p. 291-301, 2014.

MATSUNAGA, R. M. et al. Desenvolvimento de um jogo educativo para apoiar o aprendizado de pacientes com hemofilia. In: Anais do Workshop de Desafios da Computação Aplicada à Educação. [S.1.: s.n.], 2012. p. 110-119.

MELO, A. M.; BARANAUSKAS, M. C. C.; SOARES, S. C. de M. Design com crianças: da prática a um modelo de processo. Brazilian Journal of Computers in Education, v. 16, n. 01, 2008.

MENEZES, C. C. N.; BORTOLLI, R. D. Potential of gamification as assessment tool. Creative Education, Scientific Research Publishing, v. 7, n. 04, p. 561, 2016.

MESQUITA, M. A. A. et al. Utilizing gamification with social network to aid students in programming languages lessons in higher education it courses. In: SIGCSE. [S.l.: s.n.], 2014. p. 718.

MORAES, C. R.; VARELA, S. Motivação do aluno durante o processo de ensino-aprendizagem. Revista eletrónica de Educação, v. 1, n. 1, p. 1-15, 2007.

MORAIS, D.; GOMES, T.; PERES, F. Desenvolvimento de jogos educacionais pelo usuário final: uma abordagem além do design participativo. In: BRAZILIAN COMPUTER SOCIETY. Proceedings of the 11th Brazilian Symposium on Human Factors in Computing Systems. [S.1.], 2012. p. 161-164.

PETRI, G.; WANGENHEIM, C. G. von; BORGATTO, A. F. Meega+: an evolution of a model for the evaluation of educational games. INCoD/GQS, v. 3, 2016.

SCRIVEN, M. S. The methodology of evaluation (perspectives of curriculum evaluation, and aera monograph series on curriculum evaluation, no. 1). Chicago: Rand NcNally, 1967.

SOARES, L. F.; GONÇALVES, H. A.; MAGALHÃES, E. C. S. Desenvolvimento de um software (jogo 3d) para o ensino-aprendizagem de química na educação básica. 2011.

TODA, A. et al. Um processo de gamificação para o ensino superior: Experiências em um módulo de bioquímica. In: Anais do Workshop de Informática na Escola. [S.1.: s.n.], 2016. v. 22, n. 1, p. 495. 